\title{
Lỗi tại người làm dữ liệu?
}

- sciencevietnam $\mathbf{E}$ (1) August 22,2021

ENHANCED BY Google

SSHPA (22-08-2021) - Nghiên cứu năm 2012 trên PNAS (được biên tập bởi nhà kinh tế học đạt giải Nobel—Daniel Kahneman) vừa bị rút mới đây cho biết, trong các giấy tờ điền thông tin như thuế, bảo hiểm, yêu cầu người dùng ký xác nhận sự thật trước sẽ giúp giảm các hành vi gian dối.

Sau 10 năm, Signing at the beginning makes ethics salient and decreases dishonest self-reports in comparison to signing at the end đã có khoảng 440 trích dẫn trên Google Scholar [1]. Đồng thời kết quả này được sử dụng rất nhiều bởi các công ty bảo hiểm, hay trong chương trình đào tạo nhân sự của các tập đoàn lớn.
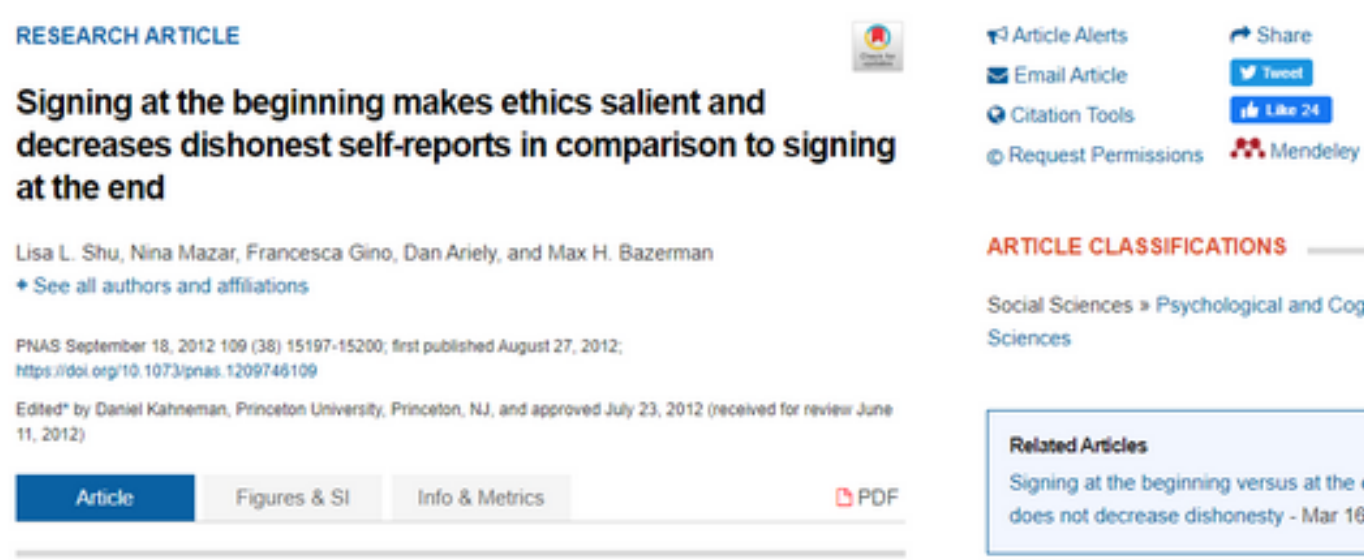
Sciences

Related Articles

Signing at the beginning versus at the end

does not decrease dishonesty - Mar 16, 2020

Bất chấp điều đó, nghiên cứu tái xác lập vào năm 2020 đã cho thấy kết quả cũ năm 2012 là không chuẩn xác [2]. Một nhóm điều tra độc lập khác sau đó đã phát hiện ra hàng loạt điểm bất thường trong dữ liệu của nghiên cứu [3]. Không chỉ đơn thuần là một vụ việc tái xác lập kết quả, dường như nghiên cứu năm 2012 còn đã sử dụng dữ liệu được làm giả.

Liên lạc với các tác giả, BuzzFeedNews cho biết 4/5 tác giả không tham gia vào quá trình làm dữ liệu. Tác giả còn lại là Dan Ariely—nhà nghiên cứ tại Duke University và diễn giả quen thuộc tại TED—cho biết ông đã phối hợp với một công ty bảo hiểu để thu thập dữ liệu [4]. Tuy vậy, khi nhiều thông tin liên quan vẫn được bảo mật, khó có thể kết luận Dan Ariely có vô tội như ông khẳng định hay không.

Hiện nay, các nhà nghiên cứu đều đã đồng ý rút bài. Vụ việc một lần nữa cho khoa học cần thay đổi nhiều hơn nữa để có thể bảo toàn sự minh bạch và trong sáng $[5,6]$. 


\section{Tài liệu tham khảo:}

[1] Shu LL, et al. (2012). Signing at the beginning makes ethics salient and decreases dishonest self-reports in comparison to signing at the end. Proceedings of the National Academy of Sciences, 109(38), 15197-15200.

[2] Kristal AS, et al. (2020). Signing at the beginning versus at the end does not decrease dishonesty. Proceedings of the National Academy of Sciences, 117(13), 7103-7107.

[3] Uri, Joe, \& Leif. (2021). Evidence of Fraud in an Influential Field Experiment About Dishonesty. Data Colada. URL: https://datacolada.org/98.

[4] Lee SM. (2021). A Big Study About Honesty Turns Out To Be Based On Fake Data. BuzzFeedNews. URL: https://www.buzzfeednews.com/article/stephaniemlee/danariely-honesty-study-retraction

[5] Vuong QH. (2018). The (ir)rational consideration of the cost of science in transition economies. Nature Human Behaviour, 2(1), 5.

[6] Vuong QH. (2020). Reform retractions to make them more transparent. Nature, 582(7811), 149.

(1) Last modified: 8/22/20213:44 PM OV Views: 22 ff 0

\section{Bài liên quan:}

- Hàng chục nghiên cứu từ Trung Quốc bị rút bỏ vì liên quan đến cấy ghéptạng tử tù

- Bốn giáo sư Đại học Kyoto tiêu xài bất chính số tiền hơn 500 triệu yên

- 400 bài báo khả nghi và câu chuyện "công xưởng làm giả nghiên cứu"

- Nhà nghiên cứu được trích dẫn cao vi phạm đạo đức biên tập và bình duyệt khoa học

- Nhà hóa học đạt giải Nobel 2018 và việc tự rút bài dũng cảm

\section{Ý kiến bạn đọc (0):}

Comment

Gửi bình luận

(c) 2018 - 2021 EASE Vietnam SciComm System. All rights reserved. Powered by Vuong \& Associates. 